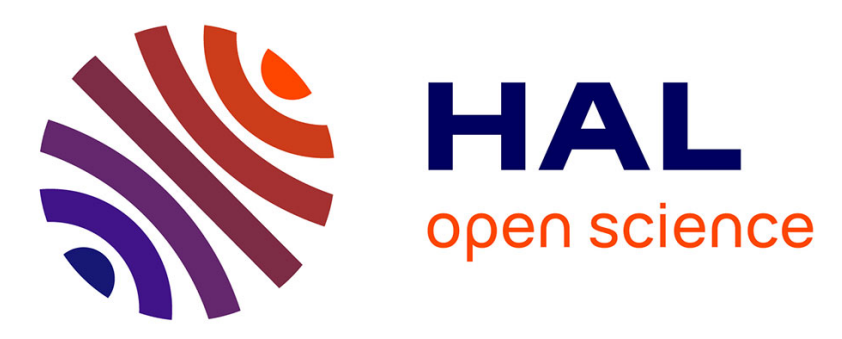

\title{
Biases in the spatial estimation of pesticide loss to groundwater
}

\author{
Yves Coquet, Dalila D. Hadjar, Jean-Marc J.-M. Gilliot, Marie-Paule \\ Charnay, Julien Moeys, Aurélie Dufour, Nicolas N. Beaudoin
}

\section{- To cite this version:}

Yves Coquet, Dalila D. Hadjar, Jean-Marc J.-M. Gilliot, Marie-Paule Charnay, Julien Moeys, et al.. Biases in the spatial estimation of pesticide loss to groundwater. Agronomy for Sustainable Development, 2005, 25 (4), pp.465-472. 10.1051/agro:2005046 . hal-02681183

\section{HAL Id: hal-02681183 https://hal.inrae.fr/hal-02681183}

Submitted on 31 May 2020

HAL is a multi-disciplinary open access archive for the deposit and dissemination of scientific research documents, whether they are published or not. The documents may come from teaching and research institutions in France or abroad, or from public or private research centers.
L'archive ouverte pluridisciplinaire HAL, est destinée au dépôt et à la diffusion de documents scientifiques de niveau recherche, publiés ou non, émanant des établissements d'enseignement et de recherche français ou étrangers, des laboratoires publics ou privés.

$$
\text { Copyright }
$$




\title{
Biases in the spatial estimation of pesticide loss to groundwater
}

\author{
Yves COQUET $^{a *}$, Dalila HADJAR ${ }^{\text {a }}$, Jean-Marc GILlIOT ${ }^{\mathrm{a}}$, Marie-Paule CHARNAYa, Julien MOEYS ${ }^{\mathrm{a}}$, \\ Alexandre DUFOUR ${ }^{\mathrm{a}}$, Nicolas BEAUDOIN ${ }^{\mathrm{b}}$ \\ ${ }^{a}$ UMR, INRA/INAPG, Environment and Arable Crops, BP 01, 78850 Thiverval-Grignon, France \\ ${ }^{\mathrm{b}}$ UR, INRA Agronomy, rue Fernand Christ, 02007 Laon Cedex, France
}

(Accepted 12 May 2005)

\begin{abstract}
Prediction of pesticide fate in soils is highly sensitive to parameters describing sorption and degradation processes, namely the $\mathrm{K}_{\mathrm{oc}}$ partioning coefficient between the soil solution and organic carbon fraction and the half-life $\mathrm{DT}_{50}$ for degradation. This paper explores the impact of getting $\mathrm{K}_{\mathrm{Oc}}$ and $\mathrm{DT}_{50}$ values either from databases or from site-specific measurements on the predicted fate of atrazine, isoproturon and metamitron on the catchment scale. Pesticide fate on the scale of the Bruyères-et-Montbérault catchment, France, was predicted using the SEAMS software that couples a one-dimensional local-scale model of pesticide fate to a geographic information system. The results show that the use of database average values for $\mathrm{K}_{\mathrm{oc}}$ and $\mathrm{DT}_{50}$ underestimates the average risk of pesticide leaching calculated from site-specific $\mathrm{K}_{\mathrm{oc}}$ and $\mathrm{DT}_{50}$ values, whereas maximised risk scenarios based on extreme $\mathrm{K}_{\mathrm{oc}}$ and $\mathrm{DT}_{50}$ values may be overestimated when using database values. Whenever available, site-specific data should be preferred to limit bias in pesticide leaching risk assessments on the catchment scale.
\end{abstract}

pesticide fate / herbicide / spatial variability / soil / environmental risk assessment

\section{INTRODUCTION}

Pesticides constitute a major environmental problem. Their widespread use in agriculture and other human activities has led to the contamination of numerous surface and groundwater resources throughout the world (Leistra and Boesten, 1989; Kolpin et al., 2000; IFEN, 2004). Environmental protection and catchment management agencies, regulatory authorities, pesticide registration offices and farmers are developing and/or using tools for the prediction of pesticide concentration levels in the various compartments of the environment (FOCUS, 1995). Concerning groundwaters, prediction of concentration levels is generally done by using a one-dimensional model describing the fate of pesticides in soil on the local scale (FOCUS, 2000; Dubus et al., 2002), coupled with a Geographic Information System (GIS) that is able to store geographicallyreferenced input data as well as mapping output modelling results (Hornsby, 1992; Sunday Tim, 1996; Corwin et al., 1997).

Predicted groundwater concentrations need to be accompanied by some estimation of their uncertainty (Vermeire and van der Zandt, 1995; Dubus et al., 2003b). Sensitivity analyses of pesticide fate models have shown predicted concentrations to be highly sensitive to input values, especially those describing sorption and degradation processes (Boesten, 1991; Dubus et al., 2003a). Sorption in soils is often described in pesticide fate models by a linear instantaneous partitioning between the soil solution and the organic carbon fraction of the soil solid phase, and characterised by the partition coefficient $\mathrm{K}_{\mathrm{oc}}$, in $\mathrm{mL} / \mathrm{g}$, where oc stands for "organic carbon" (Hamaker et Thompson, 1972). Degradation is generally modelled by a first-order kinetics, which can be characterised by the half-life, or DT50 (in days, where DT stands for "degradation time" and 50 for " $50 \%$ of the initial pesticide concentration"), of the pesticide (Beulke and Brown, 2001). These pesticide fate parameters should be measured in the various soils found in the geographic zone where the risk assessment is to be conducted. Pesticide partition coefficients and half-lives are known to be spatially variable (Elabd et al., 1986; Rao et al., 1986) and this variability should be quantified and accounted for in the risk assessment procedure. However, due to the cost of obtaining local references for such data, risk assessments are often based on generic registration data or international or national databases. These include values that have generally been measured on a variety of soils scattered over the world, but mostly in the USA and Europe.

Our objective was to test the feasibility of making sound risk assessment of groundwater contamination by pesticides on the local catchment scale using pesticide sorption and degradation databases. These "generic" assessments will be compared with others made using local information on $\mathrm{K}_{\mathrm{oc}}$ and $\mathrm{DT}_{50}$ and their variability on the catchment scale that has been previously

\footnotetext{
* Corresponding author: coquet@grignon.inra.fr
} 


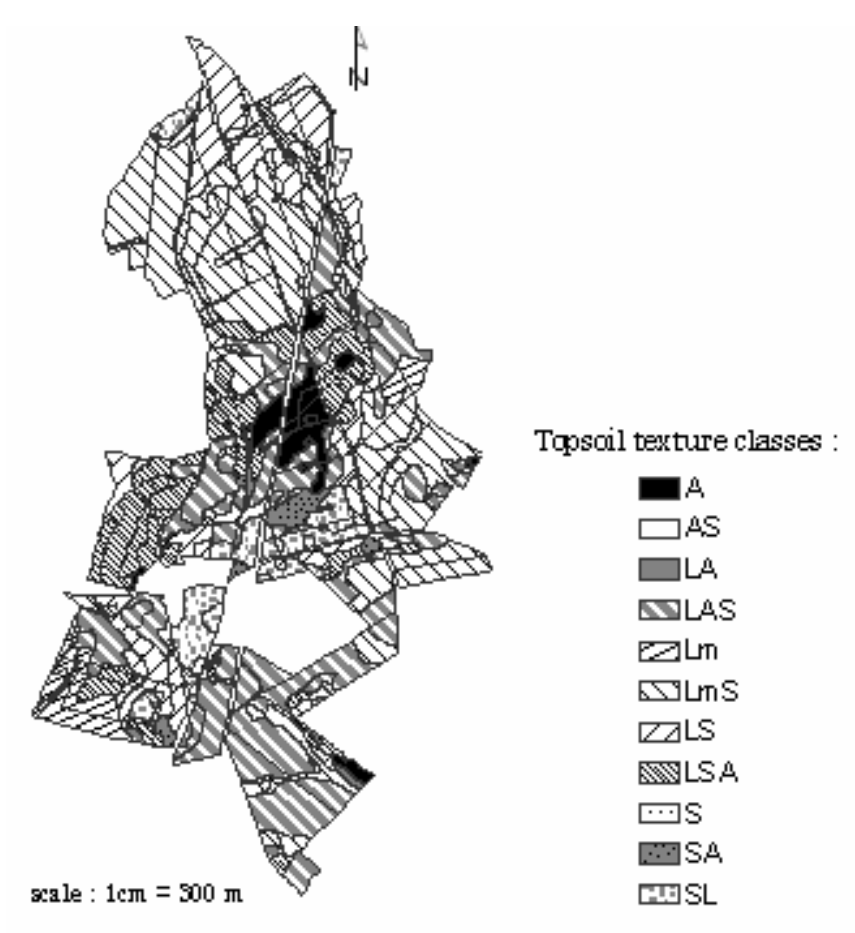

Figure 1. Map of the topsoil texture of the Bruyères-et-Montbérault catchment. Soil texture is highly variable within the catchment due to the diversity of subsoil materials (sands, loams, clays, marlstones, limestones).

obtained (Coquet and Barriuso, 2002; Charnay et al., 2005). Some general recommendations for local-scale risk assessment will then be drawn.

\section{MATERIALS AND METHODS}

\subsection{The catchment}

The catchment used for this study is located in the North of France (Aisne Département, Picardie Region) in Bruyèreset-Montbérault. Its surface area is 187 ha and includes 135 ha of cultivated land composed of 31 agricultural fields. Three farmers cultivate the fields under the same type of intensive cropping system that includes winter wheat, barley, sugar beet, rape seed and pea. Most of the fields are heterogeneous from a pedological point of view due to a high variability in parent material (Fig. 1) (Beaudoin et al., 2004). Textures range from sand to clay but the majority of the soils are loamy due the presence of partially eroded loess deposits. Twenty-one soil typological units were mapped on the 1/7500 scale (Fig. 1). Crossing the various soil mapping units with the 31 agricultural fields resulted in 190 SIMulation Units (SIMUs). Each SIMU may be regarded as homogeneous from the point of view of input data for pesticide fate modelling. The soils have a good hydraulic conductivity and runoff was very limited within the catchment. The soil water drained at the bottom of the crop root zones recharges an unconfined aquifer below the catchment. This aquifer is in turn drained by numerous springs, two of which are currently used as drinking water supplies. Traces of atrazine found in some springs have led to concern about the vulnerability of the catchment groundwater to pesticide contamination.

\subsection{The risk assessment tool}

A coupled GIS-model tool was used for the risk assessment of groundwater contamination by the agricultural pesticides used in the catchment. We used SEAMS (Soil Environmental Agricultural Management System) (Hoogeweg and Hornsby, 1999), which has been developed by the University of Florida in Gainesville and is an integration of CMLS96B (Nofzinger and Hornsby, 1986) into ArcView ${ }^{\circledR} 3.2$ (ESRI, Redlands, California). According to Corwin et al. (1997), the coupling between CMLS96B and ArcView ${ }^{\circledR}$ is of the "tight" type, which means that both the model and the GIS share a common user interface and that data exchange between the model and the GIS is transparent to the user.

CMLS96B is one of the simplest models for simulating pesticide fate in soils (Calvet, 1995). It is a one-dimensional functional model based on a tipping-buckets representation of water flow. This representation implies that CMLS96B cannot account for hydrodynamic dispersion during transport or for upward water flows such as capillary rises. Physicochemical properties are assumed to be homogeneous within each horizon. Sorption processes are assumed to respect an instantaneous, linear and reversible equilibrium. Pesticide degradation is considered to be identical in all the horizons of the soil profile and to follow the same first-order kinetics. Time-dependent sorption or water content and temperature effects on degradation rates are not included in CMLS96B. CMLS96B simulates the advance of the pesticide pulse within the soil profile and SEAMS records the following outputs from CMLS96B: the pesticide mass (mg/ha) that reaches a user-defined "control depth", for each SIMU; the travelling time (days) of the pesticide down to the "control depth"; and the "average load", which is the spatial mean of the pesticide mass that reaches the "control depth" on the catchment scale.

SEAMS manages climatic input to CMLS96B in a stochastic way by using the weather generator WGEN (Richardson and Wright, 1984). This tool produces simulated climatic series of unlimited duration for a given site based on the statistical characteristics of the local climate using Markov chain simulation. Up to 15 years of climatic data may be generated by WGEN for a SEAMS simulation. We here define one "simulation" as the one-dimensional transport modelling of a specific herbicide down to the control depth within each of the SIMUs composing the catchment. A simulation may last up to 15 years depending on the travelling time and degradation rate of the pesticide. SEAMS stops a simulation either when the pesticide reaches the control depth or when the totality of the pesticide has been degraded. Simulations have to be repeated for the same scenario to account for the variability of the climate generated by WGEN. Up to 650 simulations may be done by SEAMS to account for climate variability as recommended by Dubus and Janssen (2003). We set the number of simulations at the maximum allowed by SEAMS because of the highly non-linear 
Table I. Description of $\mathrm{K}_{\mathrm{oc}}$ and $\mathrm{DT}_{50}$ data sets for use in the risk assessment scenarios.

\begin{tabular}{|c|c|c|c|c|c|c|c|c|c|c|c|c|c|}
\hline & \multicolumn{7}{|c|}{ Database values } & \multicolumn{6}{|c|}{ Measured values } \\
\hline & & mean & nb. obs. & $\min$ & $\max$ & $\mathrm{P} 20$ & P80 & mean & nb. obs. & $\min$ & $\max$ & $\mathrm{P} 20$ & P80 \\
\hline \multirow{3}{*}{$\mathrm{K}_{\mathrm{oc}}\left(\mathrm{mL} \cdot \mathrm{g}^{-1}\right)$} & Atrazine & 123 & 13 & 38 & 174 & 88 & 157 & 63 & 51 & 52 & 83 & 55 & 72 \\
\hline & Isoproturon & 155 & 2 & 80 & 230 & - & - & 66 & 51 & 52 & 90 & 58 & 75 \\
\hline & Metamitron & 168 & 1 & - & - & - & - & 75 & 51 & 48 & 95 & 65 & 86 \\
\hline \multirow{3}{*}{$\mathrm{DT}_{50}$ (days) } & Atrazine & 69 & 13 & 18 & 120 & 45 & 110 & 32 & 51 & 12 & 39 & 27 & 35 \\
\hline & Isoproturon & 29 & 6 & 12 & 45 & 21 & 32 & 13 & 14 & 5 & 31 & 9 & 15 \\
\hline & Metamitron & 28 & 1 & - & - & - & - & 17 & 14 & 14 & 22 & 15 & 18 \\
\hline
\end{tabular}

P20: 20th percentile, $\mathrm{P} 80$ : 80th percentile.

response of CMLS96B outputs to climate variations. We here define a "prediction" as the results of the 650 simulations done to assess pesticide dissipation for a particular scenario. In the following, we will note as $m_{-S I M U}$, or "local load", the arithmetic mean of all simulations for a particular SIMU within a particular prediction, and se_sIMU the standard error of the mean of all simulations for a particular SIMU and prediction. The spatial mean, or "average load", of all $m_{- \text {SIMU values for }}$ a particular prediction will be noted as $M_{-W S}$ and the standard error of this spatial mean ( $M_{- \text {WS }}$ ) will be noted as $S E_{- \text {WS }}$. In this way, we can consider that the average value of $s e_{-}$SIMU on the catchment scale is a characterisation of the temporal variability of the risk due to climatic variation, whereas $S E_{- \text {WS }}$ characterises the spatial component of risk variability.

\subsection{Input data}

SEAMS requires input data on climate, agricultural practices, soils and pesticides. No climatic data were directly measured within the catchment. Climatic data were taken from the meteorological station of St Quentin-Roupy (Aisne Département) located $56 \mathrm{~km}$ from Bruyères-et-Montbérault. Data on maximum and minimum daily temperatures, daily solar radiation and daily rainfall from the $01 / 01 / 1986$ to $31 / 12 / 1998$ period were used to derive the statistical parameters for WGEN. Agricultural data were provided by the INRA Agronomy Station of Laon. They included the maximum rooting depth, the soil volumetric water content below which the plant suffers from water stress and the crop coefficients at the various development stages of each crop cultivated in the catchment. Soil data were also provided by the INRA Agronomy Station of Laon. Each horizon encountered in the soils of the catchment was documented by its depth boundaries, organic carbon content, bulk density, water contents at field capacity and wilting point, porosity and texture. Pesticide data included two parameters: the half-life, $\mathrm{DT}_{50}$ (days), of the pesticide and its sorption coefficient normalised by the organic carbon content, $\mathrm{K}_{\mathrm{oc}}(\mathrm{mL} / \mathrm{g})$. Data were either taken from available databases on sorption and degradation properties of pesticides (Dabène et al., 1995; Hornsby et al., 1996) or calculated from measured laboratory data (Coquet and Barriuso, 2002; Charnay et al., 2005).

\subsection{Risk assessment scenarios}

An agricultural survey of the catchment showed that up to 86 different pesticides have been used from 1989 to 1997, with the largest quantities being herbicides. From among them, we selected three herbicides as being representative of the various crops cultivated in the catchment: metamitron, used on sugar beet, ranked fourth among all the pesticides listed in the decreasing order of their accumulated load on the catchment scale during the 1989-1997 period, with a total of $484 \mathrm{~kg}$ of active ingredient; isoproturon, used on cereals, ranked eighth with a total of $228 \mathrm{~kg}$; and atrazine ranked only thirtieth with a total of $25 \mathrm{~kg}$ due to its limited use on occasional maize fields but was included because it had been the only pesticide detected in spring waters during annual surveys. SEAMS does not allow for simulation of crop successions. Therefore, risk assessments were done separately for each herbicide, considering the monoculture in the whole catchment for all the duration of each prediction.

Risk assessments need to account for the variability of input data. By construction, SEAMS accounts for climate variability through a stochastic generation of climate. All input data may be subject to variability. However, as most pesticide fate models are mostly sensitive to sorption and degradation parameters, we limited our analyses to $\mathrm{K}_{\mathrm{oc}}$ and $\mathrm{DT}_{50}$ variability impacts. Preliminary trials showed that the SEAMS results were indeed most sensitive to these two parameters. Based on the variability of the $\mathrm{K}_{\mathrm{oc}}$ and $\mathrm{DT}_{50}$ parameters in the literature or measurement databases, we designed two scenarios for the risk assessment of pesticide leaching in the Bruyères-et-Montbérault catchment.

We first designed a scenario that could account for an average leaching risk. In this scenario, the arithmetic averages of all the $\mathrm{K}_{\mathrm{oc}}$ and $\mathrm{DT}_{50}$ values either found in the databases or measured within the catchment were used (Tab. I). $\mathrm{K}_{\mathrm{oc}}$ and $\mathrm{DT}_{50}$ literature databases were those from Hornsby et al. (1996) for atrazine, and from Dabène et al. (1995) for isoproturon and metamitron, which are not included in the Hornsby et al. database. The Hornsby et al. database includes $13 \mathrm{~K}_{\mathrm{oc}}$ and $13 \mathrm{DT}_{50}$ values for atrazine. The Dabène et al. database includes $6 \mathrm{DT}_{50}$ values for isoproturon but only 2 extreme values for $\mathrm{K}_{\mathrm{oc}}$. Only one value of $\mathrm{K}_{\mathrm{oc}}$ and $\mathrm{DT}_{50}$ were available for metamitron. These two values were taken as averages for metamitron, and 
Table II. Simulation parameters used for the three herbicides in all risk assessment scenarios.

\begin{tabular}{|c|c|c|c|}
\hline Herbicide & Atrazine & Isoproturon & Metamitron \\
\hline Crop & corn & wheat & beet \\
\hline Application rate (kg/ha) & 0.95 & 1 & 8.8 \\
\hline Application dates (year n) & 1-2 May & 15-16 March & 1-2 June \\
\hline Root depth (m) & 1.2 & 1.3 & 1.5 \\
\hline Control depth (m) & 0.6 & 0.6 & 0.6 \\
\hline Number of simulations over 15 years & 650 & 650 & 650 \\
\hline
\end{tabular}

Table III. Prediction results: average load $M_{-} W S$ values in $\mathrm{mg} / \mathrm{ha}$. Standard error $\left(S E_{-} W S\right)$ is given in parentheses. Generic scenarios based on literature $\mathrm{K}_{\mathrm{oc}}$ and $\mathrm{DT}_{50}$ values underestimate the average risk of pesticide loss to groundwater compared with site-specific scenarios using $\mathrm{K}_{\mathrm{oc}}$ and $\mathrm{DT}_{50}$ measurements on the catchment scale.

\begin{tabular}{lccccc}
\hline & \multicolumn{2}{c}{ Average risk } & & \multicolumn{2}{c}{ Maximised risk } \\
\cline { 1 - 2 } \cline { 5 - 6 } & generic scenario & site-specific scenario & & generic scenario & site-specific scenario \\
\hline Atrazine & $0.19(2.40)$ & $0.417(4.21)$ & & $57.9(273.6)$ & $2.58(20.71)$ \\
Isoproturon & 0 & $0.000013(0.000033)$ & & $0.012(0.037)$ & $0.089(0.59)$ \\
Metamitron & 0 & $0.0015(0.025)$ & & - & $0.74(6.88)$ \\
\hline
\end{tabular}

an average $\mathrm{K}_{\mathrm{oc}}$ was calculated as the mean of the two available values for isoproturon. Fifty-one measured values were available for atrazine, isoproturon and metamitron $\mathrm{K}_{\mathrm{oc}} \mathrm{s}$ (Coquet and Barriuso, 2002) (Tab. I), as well as for atrazine $\mathrm{DT}_{50}$, but only 14 measured $\mathrm{DT}_{50}$ values were available for isoproturon and metamitron (Charnay et al., 2005).

Secondly, we designed a "worst-case" scenario that would maximise the leaching risk by considering a low degradation and a low sorption of the pesticide by the soils. For this scenario, we used two different approaches, whether the database was from on-site measured data or from literature surveys. When using literature databases, we used the 20th percentile for $\mathrm{K}_{\mathrm{oc}}$ and 80 th percentile for $\mathrm{DT}_{50}$ in order to exclude outliers. As only 2 values were available for isoproturon $\mathrm{K}_{\mathrm{oc}}$, we used the lowest value for the maximised risk scenario. Of course, no worst-case scenario could be constructed for metamitron from the Dabène et al. (1995) database as only one value was available for $\mathrm{K}_{\mathrm{oc}}$ and $\mathrm{DT}_{50}$. For the maximised risk scenario based on measured data, we used the extreme values of the data sets because they were indeed real values encountered in the Bruyères-et-Montbérault catchment and relevant for the evaluation of a worst-case situation on the catchment scale. Parameters related to soil properties and agricultural practices were kept constant for all risk assessments (Tab. II). In the following, we will refer to the scenarios based on literature databases as "generic" scenarios, whereas those based on the available measurements will be designated as "site-specific" scenarios.

\section{RESULTS AND DISCUSSION}

\subsection{Average risk scenarios}

For all three herbicides, the generic average risk scenario underestimates the real average leaching risk as estimated by the site-specific scenario (Tab. III). The average load $M_{- \text {WS }}$ for atrazine estimated from literature databases is half that estimated using on-site data. The groundwater contamination risk estimated from the pesticide residual mass that reaches the 60$\mathrm{cm}$ control depth decreases in the order: atrazine $>$ metamitron $>$ isoproturon. No isoproturon or metamitron reaches the $60-\mathrm{cm}$ control depth in generic scenarios, whereas 0.013 and $1.52 \mu \mathrm{g} /$ ha of isoproturon and metamitron were simulated at the $60-\mathrm{cm}$ control depth for site-specific scenarios.

Pesticide load on the SIMU scale, or "local load", is highly variable within the catchment as denoted by coefficients of variation $(\mathrm{CVs})$ of $m_{-\mathrm{SIMU}}$, calculated as the ratio of $S E_{-\mathrm{WS}}$ to $M_{-W S}$ (Tab. III), in the order of magnitude of $1000 \%$ for both types of scenarios. Values of $m_{- \text {SIMU }}$ range from 0 to a maximum of $70.6,0.0001$ and $0.43 \mathrm{mg} /$ ha for atrazine, isoproturon and metamitron, respectively, for the site-specific scenarios. The maximum local load for atrazine was only $40.5 \mathrm{mg} / \mathrm{ha}$ for the generic scenario, which means that the generic scenario also underestimates the local average leaching risk within the catchment.

The location of the maximum local load within the catchment is always the same regardless of the pesticide or the type of scenario (Fig. 2): it is a small SIMU located at the top part of the catchment with very low soil organic matter content (5.5 g C/kg dry soil). However, the pattern of the leaching risk within the catchment varies greatly according to the type of scenario (Fig. 2). Some SIMUs, in which all atrazine is degraded before reaching the control depth when considering in-situ data, have a non-zero local load when using literature databases, and vice versa.

\subsection{Maximised risk scenarios}

In contrast to the average risk assessment, generic scenarios overestimate the maximised leaching risk of atrazine within the catchment when compared with site-specific scenarios (Tab. III). 

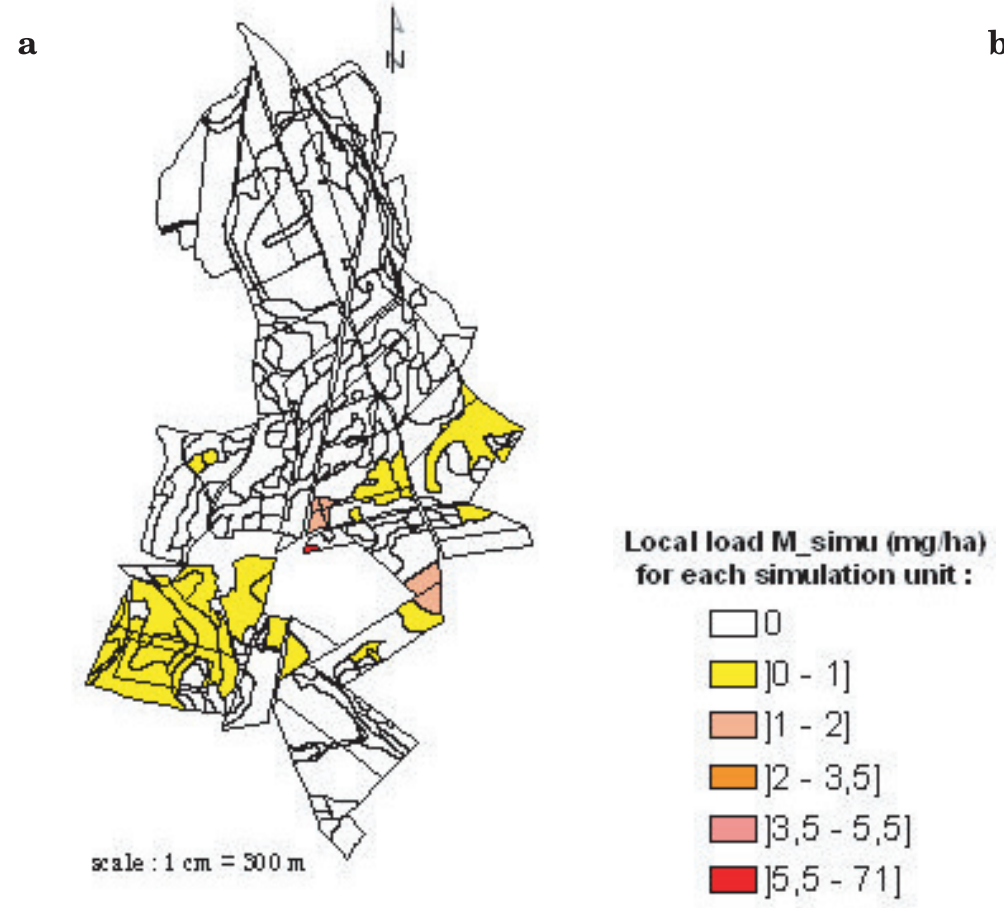

b

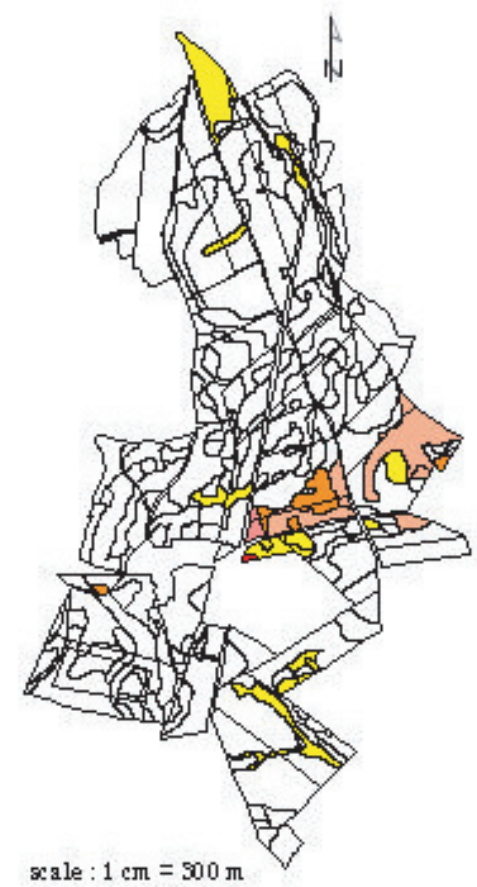

Figure 2. Prediction results for the atrazine average risk scenario: (a) with $\mathrm{K}_{\mathrm{oc}}$ and $\mathrm{DT}_{50}$ database values (Horsnby et al., 1996); (b) with $\mathrm{K}_{\mathrm{oc}}$ and $\mathrm{DT}_{50}$ measured values. The catchment-scale average load, $M_{-W S}$, is larger for prediction $\mathrm{b}$ than for prediction a. Some simulation units have non-zero local loads for prediction a but not for prediction $b$, and vice versa. The local load level for some simulation units is also variable between the two predictions $a$ and $b$.

The average load, $M_{- \text {WS }}$, is 22 times larger when estimated from the literature database percentiles than when estimated from the extreme on-site values of $\mathrm{K}_{\mathrm{oc}}$ and $\mathrm{DT}_{50}$ for atrazine, but 5 times lower for isoproturon. From the atrazine results, it seems that using the 20-percentile value for $\mathrm{K}_{\mathrm{oc}}$ and the 80-percentile value for $\mathrm{DT}_{50}$ is a reasonably conservative approach to the estimation of the maximum risk of pesticide leaching on the catchment scale. However, such a strategy does not hold for isoproturon even though the database minimum $\mathrm{K}_{\mathrm{oc}}$ value was used in place of the unavailable 20 -percentile value. This is due to the fact that this database minimum $\mathrm{K}_{\mathrm{oc}}$ value was indeed larger than the minimum $\mathrm{K}_{\mathrm{oc}}$ value measured within the catchment (Tab. I). Atrazine $M_{-\mathrm{WS}}$ at the $60-\mathrm{cm}$ depth was equivalent to a soil solution concentration of $0.52 \mu \mathrm{g} / \mathrm{L}$ for the generic scenario, and $0.018 \mu \mathrm{g} / \mathrm{L}$, for the site-specific scenario.

As for average risk scenarios, local loads are variable within the catchment. Coefficients of variation of $m_{- \text {SIMU }}$ are around $400 \%$ for generic scenarios and vary between 600 and $1000 \%$ for site-specific scenarios (Tab. III). When using site-specific scenarios, maximum local load values are $330,8.8$ and $110 \mathrm{mg} /$ ha, which represent $0.035,0.0009$ and $0.011 \%$ of the applied dose for atrazine, isoproturon and metamitron, respectively. When using generic scenarios, maximum local loads increase to 3800 and $14 \mathrm{mg} / \mathrm{ha}$; that is, 0.4 and $0.0015 \%$ of the applied dose, for atrazine and isoproturon. The location of this maximum local load within the catchment is the same for all pesticides and is identical to that recorded by the average risk scenarios.
The leaching pattern of atrazine on the catchment scale is quite consistent between the generic and site-specific scenarios (Fig. 3). When compared with the site-specific scenario, the generic scenario appears to be a translation of the simulated loads towards higher values, with a larger proportion of the catchment having non-zero $m_{-}$SIMU values. On the contrary, leaching patterns of isoproturon (Fig. 4) vary significantly between the site-specific and generic scenarios. A slightly larger zone of the catchment has a zero local load for the generic scenario compared with the site-specific one, especially in the northern part of the catchment, whereas there is a high local load zone at the southwestern end of the catchment.

Average se_SIMU values were 14.9, 0.95 and $4 \mathrm{mg} / \mathrm{ha}$ for atrazine, isoproturon and metamitron, respectively, using sitespecific scenarios. Comparing with the $S E_{-W S}$ values from Table III, we find that the temporal variability of simulated loads due to climate variations (given by the se_SIMU values) was slightly lower than the catchment-scale spatial variability (given by the $S E_{-W S}$ values), except for isoproturon. Similar types of results were obtained by Jury and Gruber (1989).

Passing from an average risk to a maximised risk assessment naturally increases the average load. Atrazine $M_{- \text {WS }}$ is multiplied by 300 when considering generic scenarios, but only by 6 when considering site-specific scenarios. Still using site-specific scenarios, $M_{- \text {Ws }}$ increases seven thousand-fold and five hundred-fold for isoproturon and metamitron, respectively. We see here that the lower the leaching risk, the higher the sensitivity of the leaching level to the $\mathrm{K}_{\mathrm{Oc}}$ and $\mathrm{DT}_{50}$ values (Boesten, 

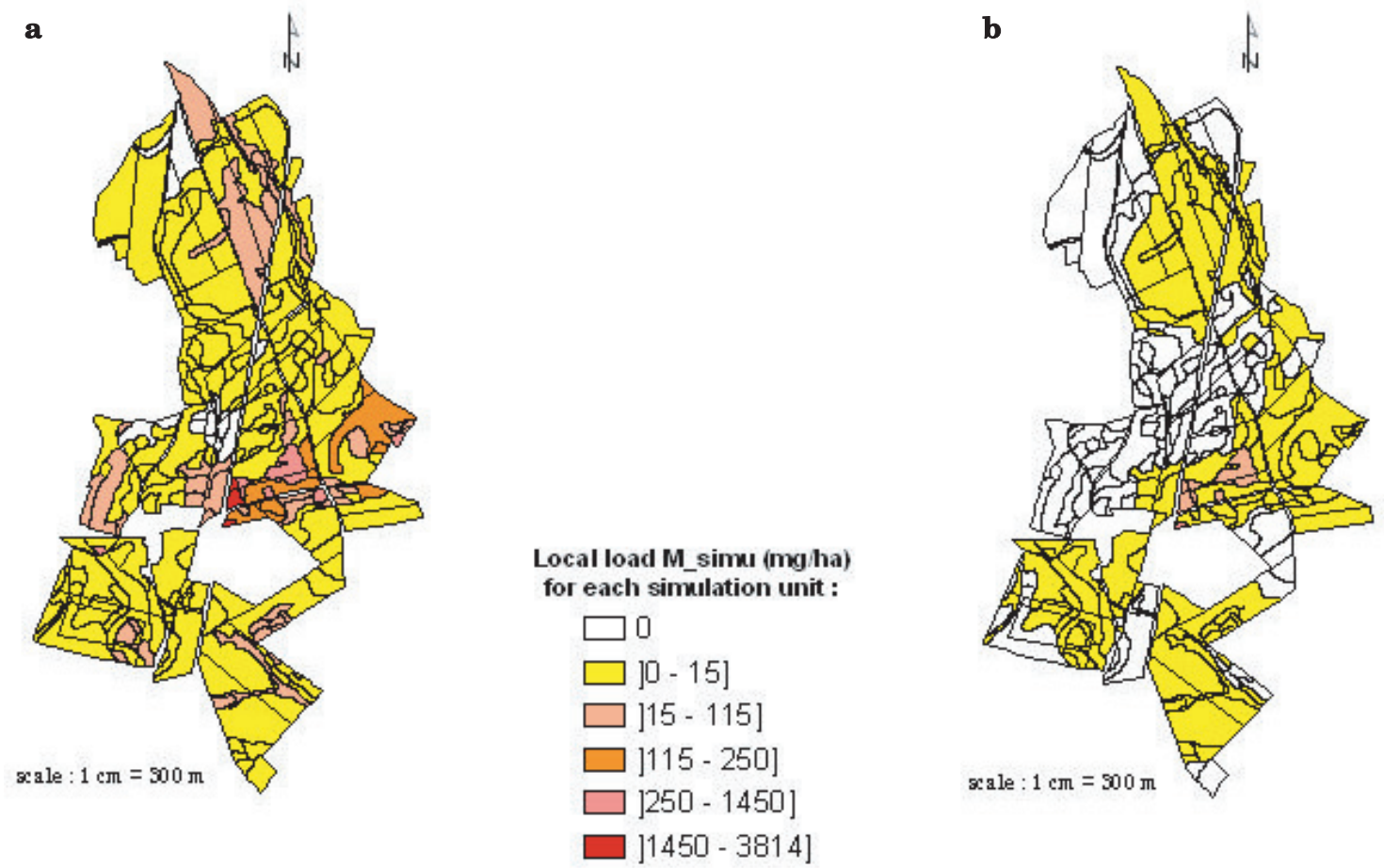

Figure 3. Prediction results for the atrazine maximised risk scenario: (a) with $\mathrm{K}_{\mathrm{oc}}$ and $\mathrm{DT}_{50}$ database values (Hornsby et al., 1996); (b) with $\mathrm{K}_{\mathrm{oc}}$ and $\mathrm{DT}_{50}$ measured values. The catchment-scale average load, $M_{-W S}$, is larger for prediction a than for prediction $\mathrm{b}$. The use of the generic scenario tends to overestimate average and local loads.

a

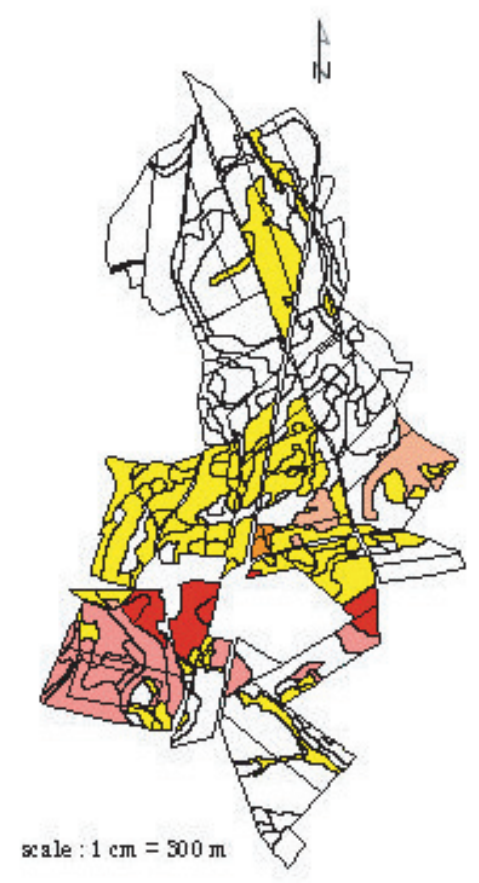

Local load M_simu (mg/ha) for each simulation unit :

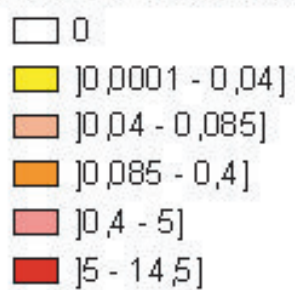

b

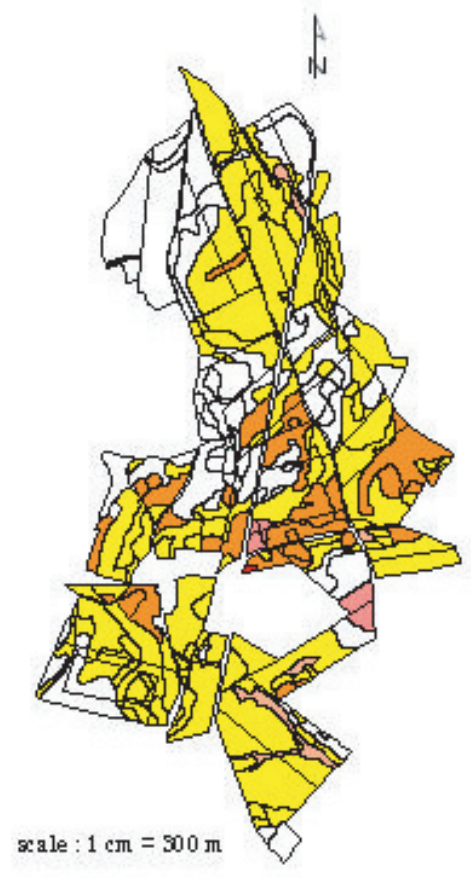

Figure 4. Prediction results for the isoproturon maximised risk scenario: (a) with $\mathrm{K}_{\mathrm{oc}}$ and $\mathrm{DT}_{50}$ database values (Dabène et al., 1995); (b) with $\mathrm{K}_{\mathrm{oc}}$ and $\mathrm{DT}_{50}$ measured values. Although the average load $M_{-W S}$ is larger for prediction $\mathrm{b}$ than for prediction a, specific simulation units (especially in the south-west of the catchment) present a much larger local load in prediction a than in prediction b: the local risk of isoproturon loss toward groundwater is largely dependent on the $\mathrm{K}_{\mathrm{oc}}$ and $\mathrm{DT}_{50}$ information source. 
Table IV. Prediction results to estimate the effect of $\mathrm{K}_{\mathrm{oc}}$ and $\mathrm{DT}_{50}$ variability on leaching risk assessment: average load $M_{-W S}$ in $\mathrm{mg} / \mathrm{ha}$. Standard error $\left(S E_{-W S}\right)$ is given in parentheses. Average load is generally more sensitive to $\mathrm{DT}_{50}$ than to $\mathrm{K}_{\mathrm{oc}}$ variations.

\begin{tabular}{|c|c|c|c|c|c|c|c|c|}
\hline & \multicolumn{4}{|c|}{ Generic scenario } & \multicolumn{4}{|c|}{ Site-specific scenario } \\
\hline & $\mathrm{K}_{\mathrm{oc}} \min$ & $\mathrm{K}_{\mathrm{oc}} \max$ & $\mathrm{DT}_{50} \max$ & $\mathrm{DT}_{50} \mathrm{~min}$ & $\mathrm{~K}_{\mathrm{oc}} \min$ & $\mathrm{K}_{\mathrm{oc}} \max$ & $\mathrm{DT}_{50} \max$ & $\mathrm{DT}_{50} \min$ \\
\hline Atrazine & $3.74(38.17)$ & $0.05(0.70)$ & $9.08(54.90)$ & $0.006(0.09)$ & $0.920(7.33)$ & $0.05(0.83)$ & $0.916(9.76)$ & $0.00007(0.0009)$ \\
\hline Isoproturon & $0.016(0.071)$ & 0 & $0.000013(0.00003)$ & 0 & $0.000003(0.00005)$ & 0 & $0.051(0.250)$ & 0 \\
\hline Metamitron & - & - & - & - & $0.098(0.969)$ & $0.00008(0.0014)$ & $0.0225(0.373)$ & $0.00005(0.00084)$ \\
\hline
\end{tabular}

1991). Finally, it is important to note that the average risk scenario based on literature data does not cover the real site-specific "worst-case" scenario (Tab. III).

\subsection{Sensitivity to input data variability}

The sensitivity of the leaching risk to climate variability is inherently considered by SEAMS. Based on average $s e_{-}$SIMU values, we estimated that the variability due to climate was of the same order of magnitude as that due to variations in soil properties within the catchment. We also showed through the comparison of average and maximised risk or generic and sitespecific scenarios that the leaching risk was highly sensitive to $\mathrm{K}_{\mathrm{oc}}$ and $\mathrm{DT}_{50}$ values.

We further explored this variability by considering $\mathrm{K}_{\mathrm{oc}}$ and $\mathrm{DT}_{50}$ variations one at a time and taking the extreme values of either the field data set or the literature database (Tab. IV). The main result from this analysis is that, generally, the variability of $\mathrm{DT}_{50}$ has a larger impact on risk assessment than the variability of $\mathrm{K}_{\mathrm{oc}}$. Taking the extreme field $\mathrm{K}_{\mathrm{oc}}$ values together with a mean field $\mathrm{DT}_{50}$ resulted in an eighteen-fold change in $M_{-\mathrm{WS}}$ for atrazine, whereas using the extreme field $\mathrm{DT}_{50}$ values and mean $\mathrm{K}_{\mathrm{oc}}$ resulted in a thirteen thousand-fold change in $M_{-\mathrm{WS}}$. When considering generic data, $M_{-}$Ws was modified by a factor of 75 due to $\mathrm{K}_{\mathrm{oc}}$ variation, but by a factor of 1500 due to $\mathrm{DT}_{50}$ variation (Tab. IV).

The same type of result was also obtained for isoproturon with site-specific data, whereas $M_{- \text {ws }}$ was found to be more sensitive to $\mathrm{K}_{\mathrm{oc}}$ variation in the literature database than to $\mathrm{DT}_{50}$ variation. This result may be attributed to the limited range of $\mathrm{DT}_{50}$ variation found in the Dabène et al. database, compared with the $\mathrm{DT}_{50}$ variation for atrazine found in the Hornsby database (Tab. I). Metamitron $M_{- \text {WS }}$ was found to be highly sensitive to $\mathrm{K}_{\mathrm{oc}}$ field variation, and as much as to $\mathrm{DT}_{50}$ field variation. However, the range of metamitron $\mathrm{DT}_{50}$ values measured in the catchment was particularly low, when compared with that of atrazine or isoproturon (Tab. I).

\subsection{SEAMS limitations}

Although SEAMS comes as a useful integrated tool for pesticide leaching risk assessment, it is subject to some drawbacks or limitations. Some of them are related to the pesticide fate model CMLS96B. The most important one is probably the fact that degradation rates are similar in the surface and subsoil. Yet, degradation rates are known to decrease dramatically with depth (Di et al., 1998; Charnay et al., 2005). As a consequence, pesticide degradation in the soil profile was probably overes- timated. In our risk assessment scenarios, no pesticide reached the 1-m depth, which is generally the reference depth considered in groundwater contamination risk assessments (FOCUS, 2000). As a consequence, we chose to displace the SEAMS control depth to $60 \mathrm{~cm}$ in order to get proper relative risk assessments, considering that no degradation was occurring between the 60 - and 100-cm depths. Other models could have been used in place of CMLS96B for the purpose of simulating the local fate of the pesticides. We used CMLS96B as a component of SEAMS, which was the only GIS-coupled pesticide fate model tool at hand freely available when we started our work. However, other tools such as GeoPEARL (Tiktak et al., 2003) could be used for similar purposes.

Another limitation was related to the maximum number of simulations that could be performed within the same prediction. Preliminary tests showed that the average load $M_{- \text {WS }}$ was highly variable between repeated predictions of the same scenario when using less than 500 simulations per prediction. Therefore, the number of simulations was set to the maximum allowed by SEAMS, 650, in all predictions. Yet, some variability of $M_{-}$WS could still be detected, which means that the prediction associated with a particular scenario was not strictly repeatable. The standard error of the mean for 8 successive predictions of the maximised risk scenarios was 1.01, 0.14 and $0.61 \mathrm{mg} / \mathrm{ha}$ for atrazine, isoproturon and metamitron, respectively, which is less than the temporal and spatial variability as judged from $s e_{-}$SIMU mean values and $S E_{-}$Ws values (Tabs. III, IV). Dubus and Janssen (2003) showed that the number of simulations per prediction should be at least 5000 in order to achieve a sufficient stability in the stochastic modelling results.

\subsection{Recommendations for pesticide leaching risk assessment}

Some basic recommendations can be made in the light of the results presented here.

1. The use of average values from literature databases is not satisfactory for the purpose of catchment-scale risk assessment. Whenever data on the spatial variability of sorption and degradation processes in the soils of the catchment are available (or in soils known to be similar to them), that information should be used preferentially.

2. When no local data is available, the use of database 20 and 80 percentiles or, by default, extreme values for $\mathrm{K}_{\mathrm{oc}}$ and $\mathrm{DT}_{50}$ should be used. Such values seem to be conservative and may be recommended for risk assessments. 
3. Databases on $\mathrm{K}_{\mathrm{oc}}$ and $\mathrm{DT}_{50}$ should include at least average (or median) and extreme values for all pesticides in current use.

However, it is difficult to know to what extent such recommendations will be generally applicable to the various catchment situations. Additional analyses such as the one presented here are needed before being able to reach the goal of making reasonably sound risk assessments.

\section{CONCLUSIONS}

We showed that pesticide leaching risk assessments were crucially dependent on the available $\mathrm{K}_{\mathrm{Oc}}$ and $\mathrm{DT}_{50}$ information. In our case study on the fate of atrazine, isoproturon and metamitron, the average risk evaluated using mean $\mathrm{K}_{\mathrm{oc}}$ and $\mathrm{DT}_{50}$ values extracted from literature databases was seriously underestimated when compared with that made by using field-measured data. Using 20-percentile and 80-percentile literature database values for $\mathrm{K}_{\mathrm{oc}}$ and $\mathrm{DT}_{50}$ overestimated the maximised risk as estimated from the extreme field $\mathrm{K}_{\mathrm{oc}}$ and $\mathrm{DT}_{50}$ values and may be regarded as a conservative approach. A simplified sensitivity analysis showed that $\mathrm{DT}_{50}$ variability had a larger impact on risk assessment than $\mathrm{K}_{\mathrm{OC}}$ variability for all three herbicides.

Acknowledgements: The authors wish to thank Gerco Hoogeweg, the creator of the SEAMS software, for helping us getting started and customising SEAMS for the purpose of our pesticide risk assessment exercise. We thank the Laon Agronomy Unit for helping us with the collection of soil and climate properties, Jean Maucorps for his insights into the pedology and geology of the Bruyères-et-Montbérault catchment, Céline van Laethem and the Chambre Départementale d'Agriculture de 1'Aisne, Service Agriculture et Environnement, for collecting the information on agricultural practices, and finally, the three farmers of the Bruyères-et-Montbérault catchment for their welcome and interest in our work. We gratefully acknowledge the financial support of the French Agency for Environment and Energy Management (contract No. 97.01.002) in the initiation of this work.

\section{REFERENCES}

Beaudoin N., Parnaudeau V., Mary B., Makowski D., Meynard J.M. (2004) Simulation de l'impact de différents scénarios agronomiques sur les pertes de nitrate à l'échelle d'un bassin hydrologique, in: Monestiez P., Lardon S., Seguin B. (Eds.), Organisation spatiale des activités agricoles et processus environnementaux, Coll. Science Update, INRA Éditions, pp. 117-141.

Beulke S., Brown C.D. (2001) Evaluation of methods to derive pesticide degradation parameters for regulatory modelling, Biol. Fertil. Soils $33,558-564$.

Boesten J.J.T.I. (1991) Sensitivity analysis of a mathematical model for pesticide leaching to groundwater, Pestic. Sci. 31, 375-388.

Calvet R. (1995) Modelling pesticide leaching in soils; main aspects and main difficulties, Eur. J. Agron. 4, 473-484.

Charnay M.P., Tuis S., Coquet Y., Barriuso E. (2005) Spatial variability in ${ }^{14} \mathrm{C}$-herbicide degradation in surface and subsurface soils, Pest Manag. Sci., 61, 845-855.

Coquet Y., Barriuso E. (2002) Spatial variability of pesticide adsorption within the topsoil of a small agricultural catchment, Agronomie 22, 389-398.

Corwin D.L., Vaughan P.J., Loague K. (1997) Modeling nonpoint source pollutants in the vadose zone with GIS, Environ. Sci. Technol. 31, 2157-2175.

Dabène F., Marié F., Smith C. (1995) Substances actives phytosanitaires. Caractéristiques utiles pour l'évaluation du comportement de quel- ques substances actives dans l'environnement, MAPA-DERFBARNS.

Di H.J., Aylmore L.A.G., Kookana R.S. (1998) Degradation rates of eight pesticides in surface and subsurface soils under laboratory and field conditions, Soil Sci. 163, 404-411.

Dubus I.G., Janssen P.H.M. (2003) Issues of replicability in Monte Carlo modelling: a case study with a pesticide leaching model, Environ. Toxicol. Chem. 22, 3081-3087.

Dubus I.G., Beulke S., Brown C.D. (2002) Calibration of pesticide leaching models: critical review and guidance for reporting, Pest Manag. Sci. 58, 745-758.

Dubus I.G., Beulke S., Brown C.D. (2003a) Sensitivity analyses for four pesticide leaching models, Pest Manag. Sci. 59, 962-982.

Dubus I.G., Brown C.D., Beulke S. (2003b) Sources of uncertainty in pesticide fate modelling, Sci. Total Environ. 317, 53-72.

Elabd H., Jury W.A., Cliath M.M. (1986) Spatial variability of pesticide adsorption parameters, Environ. Sci. Technol. 20, 256-260.

FOCUS (FOrum for the Coordination of pesticide fate models and their USe) (1995) Modelling environmental fate of plant protection products in the context of their authorization within the European Union. European Commission/Directorate General for Agriculture, Document Reference 1694/VI/95.

FOCUS (FOrum for the Coordination of pesticide fate models and their USe) (2000) FOCUS groundwater scenarios in the EU plant protection product review process. Report of the FOCUS Groundwater Scenarios Workgroup, EC, Document Reference Sanco/321/2000.

Hamaker J.W., Thompson J.M. (1972) Adsorption, in: Goring C.A.I., Hamaker J.W. (Eds.), Organic chemicals in the soil environment, Vol. 1, Marcel Dekker, New York, pp. 51-143.

Hoogeweg C.G., Hornsby A.G. (1999) Soil, environmental and agricultural management system, SEAMS Version 1.1 User's Manual, Circular SW112, Soil and Water Science Department, University of Florida.

Hornsby A.G. (1992) Site-specific pesticide recommendations: the final step in environmental impact prevention, Weed Technol. 6, 736-742.

Hornsby A.G., Wauchope R.D., Herner A.E. (1996) Pesticides properties in the environment, Springer Verlag, New York.

Institut Français de l'Environnement (IFEN) (2004) Les pesticides dans les eaux. Sixième bilan annuel. Année 2002 (Pesticides in waters. Sixth annual report. 2002 data), Étude et Travaux $n^{\circ} 42$, IFEN/ RNDE.

Jury W.A., Gruber J. (1989) A stochastic analysis of the influence of soil and climatic variability on the estimate of pesticide groundwater pollution potential, Water Resour. Res. 25, 2465-2474.

Kolpin D.W., Barbash J.E., Gilliom R.J. (2000) Pesticides in ground water of the United States, 1992-1996, Ground Water 38, 858-863.

Leistra M., Boesten J.J.T.I. (1989) Pesticide contamination of groundwater in Western Europe, Agric. Ecosyst. Environ. 26, 369-389.

Nofziger D.L., Hornsby A.G. (1986) A microcomputer-based management tool for chemical movement in soil, Appl. Agric. Res. 1, 50-56.

Rao P.S.C., Edvardsson K.S.V., Ou L.T., Jessup R.E., Nkedi-Kizza P., Hornsby A.G. (1986) Spatial variability of pesticide sorption and degradation parameters, in: Garner W.Y., Honeycutt R.C., Nigg H.N. (Eds.), Evaluation of pesticides in ground water, ACS Symposium Series 315, American Chemical Society, Washington, DC, pp. $100-115$.

Richardson C.W., Wright D.A. (1984) WGEN: a model for generating daily weather variables, USDA-ARS Report.

Sunday Tim U. (1996) Coupling vadose zone models with GIS: emerging trends and potential bottlenecks, J. Environ. Qual. 25, 535-544.

Tiktak A., van der Linden A.M.A., Boesten J.J.T.I. (2003) The GeoPEARL model. Model description, applications and manual, RIVM report 716601007/2003, RIVM, Bilthoven, The Netherlands.

Vermeire T., van der Zandt P. (1995) Procedures of hazard and risk assessment, in: van Leeuwen C.J., Hermens J.L.M. (Eds.), Risk assessment of chemicals: an introduction, Kluwer Academic Publishers, pp. 293-337. 